\title{
Monitoring of hepatic venous oxygen saturation for predicting acute liver dysfunction after Fontan operations
}

Acute liver dysfunction after Fontan operations may result from inadequate hepatic perfusion along with low cardiac output and high central venous pressure. We monitored hepatic venous oxygen saturation in $\mathbf{1 5}$ patients after Fontan operations to determine whether oxygen saturation predicts the occurrence and severity of acute liver dysfunction. We measured oxygen saturation from hepatic venous blood samples every 4 to 5 hours for at least 24 hours after the operation and used the mean hepatic venous oxygen saturation value for the first $\mathbf{2 4}$ hours after the operation to analyze the relationship between oxygen saturation and hepatic function. As indices of hepatic function, we measured serum alanine aminotransferase, total bilirubin, blood lactate (arterial, hepatic venous, and the difference between them), and the arterial ketone body ratio (the ratio of aceto-acetate to $\beta$-hydroxybutyrate). For alanine aminotransferase and bilirubin, we used the maximal values during the first week in the analysis, and for blood lactate and ketone body ratio, we used the mean values for the first 24 hours after the operation. Significant broken-line regression relationships existed between mean hepatic venous oxygen saturation and hepatic function indices (alanine aminotransferase, total bilirubin, and blood lactate). The interpretation of these relationships is that hepatic indices are constant above the critical mean hepatic venous oxygen saturation values but are correlated with mean hepatic venous oxygen saturation below critical points in the range of $21 \%$ to $26 \%$. Thus a hepatic venous oxygen saturation value below about $25 \%$ during the first 24 hours after a Fontan operation predicts the occurrence and the severity of acute liver dysfunction. We suggest that monitoring hepatic venous oxygen saturation is useful for management of critically ill patients after Fontan operations. (J Thorac Cardiovasc Surg 1994;108:700-8)

Hiroshi Takano, MD, Hikaru Matsuda, MD, Keishi Kadoba, MD, Hiroaki Kawata, MD, Yoshiki Sawa, MD, Yasuhisa Shimazaki, MD, and Nobuyuki Taenaka, MD, Osaka, Japan

\footnotetext{
A cute liver dysfunction, characterized by sharp increases in concentrations of serum transaminase and bilirubin, though infrequent, is a major complication after cardiac surgery. ${ }^{1,2}$ This complication is particularly likely to develop in patients who undergo Fontan operations, which bypass the right ventricle. After this type of operation, cardiac output is likely to be low and central venous

From the Department of Surgery and Intensive Care Unit, Osaka University Medical School, Suita, Osaka, Japan.

Received for publication Nov. 2, 1993.

Accepted for publication April 7, 1994.

Address for reprints: Hikaru Matsuda, MD, 2-2 Yamadaoka, Suita, Osaka, 565, Japan

Copÿright 1994 by Mosby-Year Book, Inc.

$0022-5223 / 94 \$ 3.00+0 \quad \mathbf{1 2 / 1 / 5 6 6 9 8}$
}

pressure high. These altered hemodynamics may decrease blood flow to the liver, thus causing hypoxia in hepatic tissue, which in turn damages hepatic cells and ultimately manifests as acute liver dysfunction. ${ }^{3.4}$ In addition, coagulation system disorders resulting in bleeding tendency ${ }^{3}$ or venous thrombosis ${ }^{5}$ have also been reported as an early complication of Fontan operations. Therefore it is important to prevent liver dysfunction.

For this purpose, it is necessary to be able to predict the occurrence and severity of acute liver dysfunction. Prediction based on hemodynamic variables is complicated because many hemodynamic variables may interact with each other and thus affect hepatic perfusion. ${ }^{4,6,7} \mathrm{~A}$ more reliable prediction might be based on hepatic perfusion status, which can be assessed by measuring hepatic venous oxygen saturation $\left(\mathrm{ShvO}_{2}\right)$, as a reflection of oxy- 

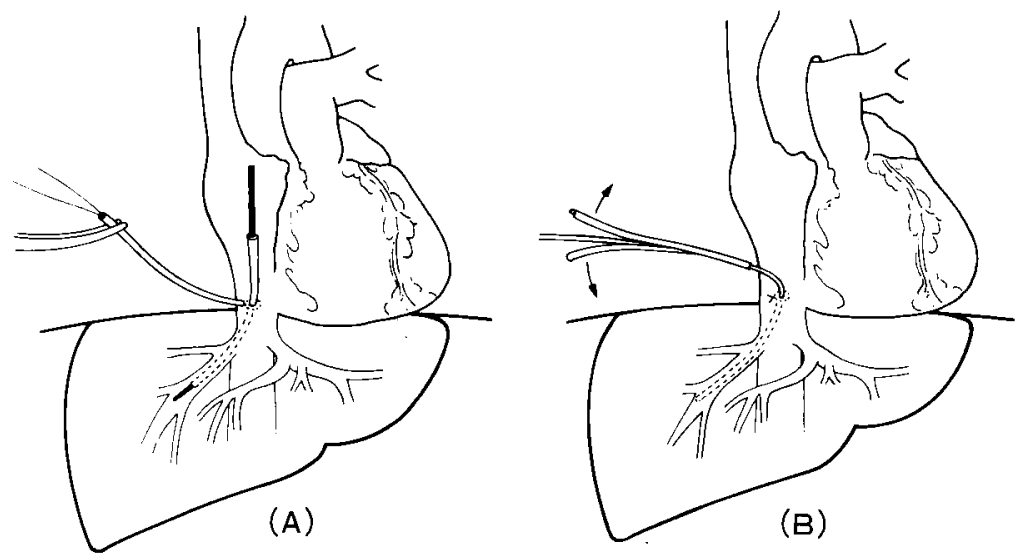

Fig. 1. The method of placing a blood sampling catheter in the hepatic vein during cardiac operation. A curved metal stylet inside a sheath is inserted into the right hepatic vein through a small atriotomy secured with a pursestring suture (A). The stylet is withdrawn and a soft catheter is inserted through the sheath. The sheath is then withdrawn and peeled off the catheter (B). An additional pursestring suture of elastic thread is placed around the site of insertion to prevent bleeding on withdrawal.

gen supply-demand relationship. ${ }^{8,9}$ This predictor was suggested by our observation that $\mathrm{ShvO}_{2}$ was extremely low in three patients who had acute liver dysfunction after Fontan operations. ${ }^{4}$ We here report that monitoring $\mathrm{ShvO}_{2}$ predicts the occurrence and the severity of acute liver dysfunction in patients after Fontan operations.

\section{Patients and methods}

Patients. Fifteen consecutive patients who underwent a modified Fontan operation were studied. Their ages ranged from 3 to 20 years $(6.9 \pm 4.7$, mean \pm standard deviation $)$. Major cardiac anomalies were single right ventricle in six patients, single left ventricle in two patients, tricuspid atresia in three patients, mitral atresia in two patients, and pulmonary atresia with intact ventricular septum in two patients. Pulmonary vascular resistance before the operation ranged from 0.7 to $4.0 \mathrm{U} \cdot \mathrm{m}^{2}\left(1.9 \pm 0.9 \mathrm{U} \cdot \mathrm{m}^{2}\right)$. No patient had evidence of hepatic dysfunction, as determined by routine biochemical testing. Operative procedures were atriopulmonary connection in eight patients and total cavopulmonary connection in the other seven patients. Anesthesia was maintained with fentanyl $(0.05$ to $0.1 \mathrm{mg} / \mathrm{kg}$ ). Halothane was not used in these patients. Cardiopulmonary bypass was performed at moderate hypothermia (lowest blood temperature $24^{\circ}$ to $28^{\circ} \mathrm{C}$ ), and cardiopulmonary bypass time ranged from 90 to 242 minutes. One patient died of septicemia and one of pulmonary venous obstruction on postoperative days 95 and 46, respectively. The other 13 patients were discharged without significant complications. The study was approved by the institutional human research committee, and informed consent was obtained from each patient's parents.

Technique of catheterizing the hepatic vein. After cardiopulmonary bypass, a curved metal stylet inside a sheath was inserted into the right hepatic vein through a small atriotomy secured with a pursestring suture at the junction of the right atrium and the inferior vena cava. It was easily confirmed that the stylet was in the right hepatic vein because the right hepatic vein advanced toward the right, away from the inferior vena cava. The stylet was then withdrawn and a smaller catheter was advanced through the sheath. The catheter was advanced until it met resistance at the end of the hepatic vein; then it was withdrawn by about $2 \mathrm{~cm}$ to avoid wedging. The sheath was withdrawn and peeled off, with the catheter left in place. An additional elastic pursestring suture was placed around the site of insertion to prevent bleeding when the catheter was later withdrawn (Fig. 1). The other end of the catheter was brought outside transcutaneously. Proper position of the catheter was confirmed by postoperative radiograph in all patients. Usually, this catheter was removed on the second or third postoperative day before removal of the mediastinal drain.

\section{Methods of measurement}

Blood hemoglobin oxygen saturation. In each patient, arterial, hepatic venous, and superior vena caval blood were collected anaerobically through catheters inserted into the radial artery, hepatic vein, and superior vena cava, respectively. Blood hemoglobin and hemoglobin oxygen saturation were measured by a hemoximeter (OSM-3, Radiometer, Copenhage, Denmark). Measurements were made immediately after the patient was admitted to the intensive care unit and were repeated every 4 to 5 hours for at least 24 hours (six or seven times during the first 24 hours). In five patients, we inserted a $4 \mathrm{~F}$ fiberoptic catheter (Opticath model U440, Oximetrix, Mountain View, Calif.) into the hepatic vein and monitored $\mathrm{ShvO}_{2}$ continuously. Hemoglobin oxygen saturation was also measured with the hemoximeter every 4 to 5 hours in these patients.

Hepatic function. We measured two indices of hepatic cellular damage, serum alanine aminotransferase (ALT) and total bilirubin concentration, at least twice a day for at least 1 week after the operation.

In 13 patients, we measured blood lactate concentration (as an index of hepatic lactate metabolism) in arterial and hepatic venous blood at the same time as the blood oxygen saturation 


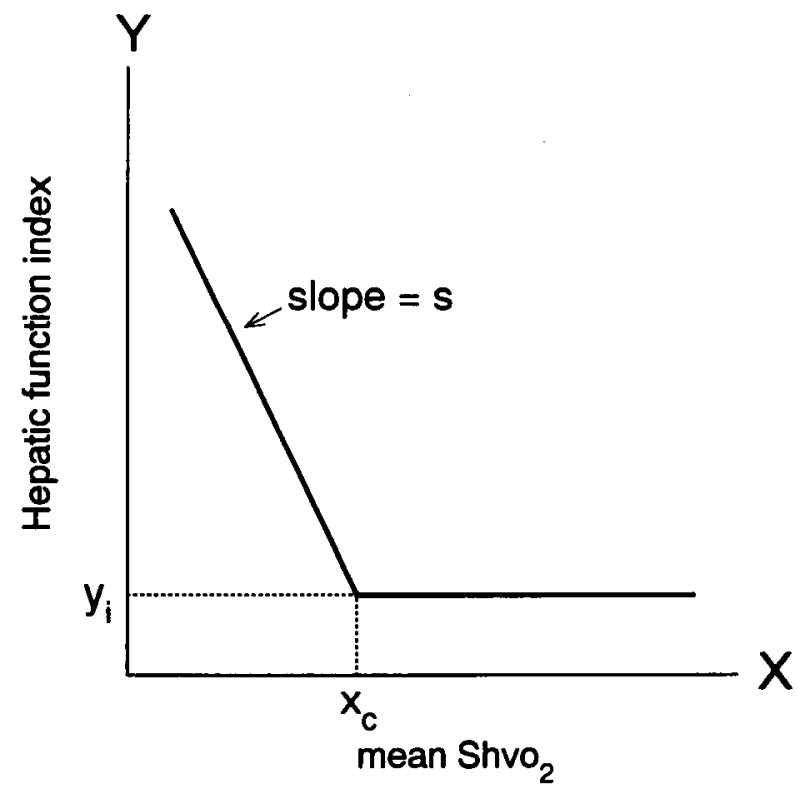

Fig. 2. Broken-line relationship between hepatic venous oxygen saturation $\left(\mathrm{ShvO}_{2}\right)$ and hepatic function. The hepatic function index remains at $y_{i}$ independent of $\mathrm{ShvO}_{2}$ above the critical $\mathrm{ShvO}_{2}$ level $\left(x_{c}\right)$ but is correlated with $\mathrm{ShvO}_{2}$ with a slope $(s)$ below the critical level $\left(\mathrm{x}_{\mathrm{c}}\right)$.

measurement. We also calculated the difference between arterial and hepatic venous lactate concentration.

In seven patients, we measured arterial ketone body ratio (as an index of hepatic mitochondrial oxidation-reduction [redox] state) at the same time as the blood oxygen saturation and lactate measurements. Arterial ketone body ratio was obtained as a ratio of aceto-acetate to $\beta$-hydroxybutyrate. This ratio reflects hepatic mitochondrial nicotinamide-adenine dinucleotide/nicotinamide-adenine dinucleotide, reduced. ${ }^{10}$ The patient's prognosis is poor when this ratio persistently drops below $0.4 .^{11}$

ALT and bilirubin were measured spectrophotometrically by an automated analyzer (Hitachi type-736, Tokyo, Japan). Lactate and ketone bodies were measured enzymatically as described elsewhere. ${ }^{12-14}$ The enzymes for aceto-acetate and $\beta$-hydroxybutyrate measurements were purchased from Sanwa Kagaku Co. Ltd. (Nagoya, Japan) and other enzymes from Boehringer Mannheim GmbH (Mannheim, Germany).

Hemodynamics. Mean arterial pressure and central venous pressure (CVP) were monitored continuously. Cardiac index was measured at least twice during the first 24 hours after the operation by the dye-dilution method (injection into the left atrium and detection in the radial artery) in 11 patients.

Postoperative management. Inotropic support (dopamine, dobutamine, or isoproterenol) and a vasodilator (prostaglandin $\mathbf{E}_{1}$ ) were used in most patients. Postoperative management was based primarily on hemodynamic variables, and all efforts were made to improve the hemodynamic variables when they deteriorated.

\section{Data analysis.}

The relationship between $\mathrm{Shvo}_{2}$ and hepatic function. For $\mathrm{ShvO}_{2}$, we computed the mean values during the first 24 hours after the operation and used them in the analysis of the relationship between $\mathrm{ShvO}_{2}$ and hepatic function. We denoted these values with the prefix mean. The reason we used the mean $\mathrm{ShvO}_{2}$ value for the first 24 hours after the operation is that ischemic hepatitis (severe hepatic dysfunction that occurs after circulatory shock) has been reported to develop when shock lasts for 24 hours. ${ }^{15}$ In assessing the hepatic function indices, we used two different types of values. For ALT and total bilirubin, we used maximal values during the first operative week and denoted them with the prefix max. For lactate concentration and arterial ketone body ratio, we computed the mean values as described earlier and used them in the analysis. The reason we distinguished these values as max and mean is that ALT and total bilirubin change rather slowly, whereas blood lactate and ketone body ratio change quickly along with the hepatic condition.

Because oxygen consumption remains relatively constant above the critical oxygen delivery level, and decreases in proportion to the decrease in oxygen delivery below the critical delivery level, 8,16,17 we analyzed the relationship between $\mathrm{ShvO}_{2}$ and hepatic function with the broken-line regression ${ }^{18}$ :

$$
Y= \begin{cases}y_{i}+s\left(X-x_{c}\right) & \text { if } X \leq x_{c} \\ y_{i} & \text { if } X>x_{c}\end{cases}
$$

where $\mathrm{Y}=$ the hepatic function index, $\mathrm{y}_{\mathrm{i}}=$ independent (constant) value for the hepatic function index where $X>x_{c}$, $\mathrm{s}=$ slope of the regression line where $\mathrm{X} \leq \mathrm{x}_{\mathrm{c}}, \mathrm{X}=\mathrm{ShvO}_{2}$, and $\mathrm{x}_{\mathrm{c}}=$ the critical value in $\mathrm{ShvO}_{2}$ where the line bends (Fig. 2). In this relationship, above the critical $\mathrm{ShvO}_{2}$ level $\mathrm{x}_{\mathrm{c}}$, hepatic function is independent of $\mathrm{ShvO}_{2}$. However, below $\mathrm{x}_{\mathrm{c}}$ hepatic function linearly depends on $\mathrm{ShvO}_{2}$ with a slope of $\mathrm{s}$. The parameters $y_{j}, s$, and $x_{c}$ were estimated by nonlinear least squares with the Marquard-Levennberg algorithm. ${ }^{19}$

The relationship between $\mathrm{ShvO}_{2}$ and hemodynamics. To determine which hemodynamic factors affect $\mathrm{ShvO}_{2}$, we examined the relationship between mean $\mathrm{ShvO}_{2}$ and the mean values (for the first 24 hours) of hemodynamic and other variables by multiple linear regression. As the hemodynamic variables, we used mean arterial pressure, CVP, cardiac index, blood hemoglobin, arterial oxygen saturation, and superior vena caval oxygen saturation. The other variables we used were doses of inotropic agents and vasodilators because these supportive drugs have been reported to influence hepatic blood flow. ${ }^{20,21}$ The analysis was made with the forward stepwise selection method with $\mathrm{F}_{\text {enter }}=4.0$ and $\mathrm{F}_{\text {remove }}=3.9$.

Statistical analysis. Data are summarized as mean \pm standard deviation for basic statistics. In the broken-line regression analysis, each parameter is reported as the estimate \pm the standard error of the estimate, and the associated $t$ statistic was tested for statistical significance.

Statistical analysis was done with SigmaStat Release 1.02 (Jandel Scientific, San Rafael, Calif.). Statistical significance was based on a $p$ value less than 0.05 .

\section{Results}

Postoperative course of a patient with acute liver dysfunction. A typical postoperative course of a patient in whom acute liver dysfunction developed is shown in Fig. 3. In this patient, the CVP rose to 20 to $25 \mathrm{~mm} \mathrm{Hg}$ early after the operation. Cardiac output remained in the relatively low range of 2.0 to $2.4 \mathrm{~L} / \mathrm{min} /$ per square meter 

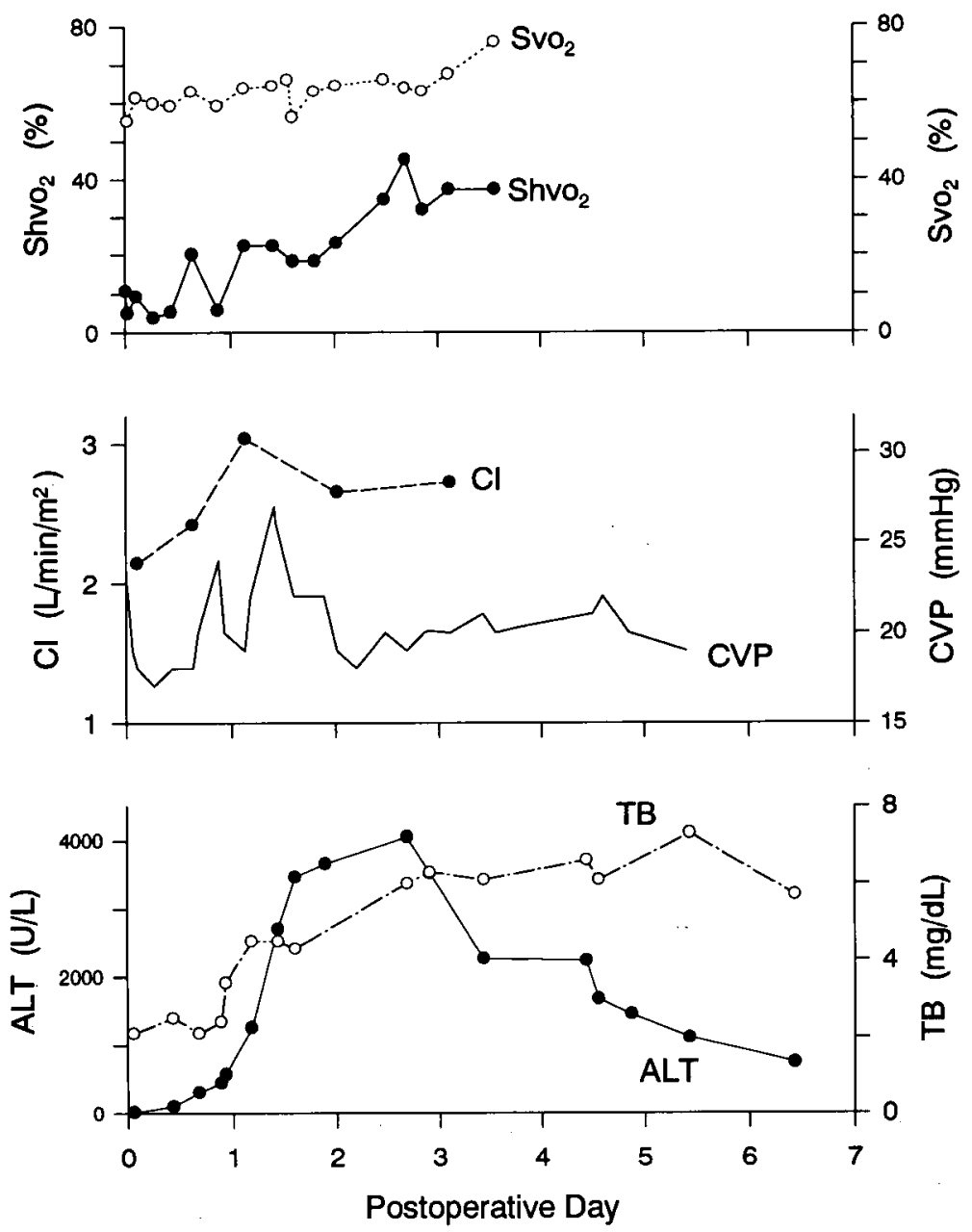

Fig. 3. Postoperative change in venous oxygen saturations, hemodynamics, and hepatic function in a patient who had acute liver dysfunction after a Fontan operation. $\mathrm{Shvo}_{2}$, Hepatic venous oxygen saturation; $\mathrm{SvO}_{2}$, superior vena caval oxygen saturation; $C I$, cardiac index; $C V P$, central venous pressure; $A L T$, serum alanine aminotransferase; $T B$, serum total bilirubin.

on the first operative day. $\mathrm{ShvO}_{2}$ was low (below $10 \%$ ) immediately after the operation. It rose to $20 \%$ on the second postoperative day and to $30 \%$ to $40 \%$ on the third day. Simultaneously measured superior vena caval oxygen saturation ranged from $55 \%$ to $70 \%$. ALT concentration started increasing about 24 hours after the operation, reaching the maximum value of $4050 \mathrm{U} / \mathrm{L}$ on the third postoperative day. Total bilirubin concentration started increasing slightly later than the ALT did, reaching $7.3 \mathrm{mg} / \mathrm{dl}$ on the sixth postoperative day. It took more than 1 month for total bilirubin to return to normal.

Relationship between the $\mathrm{Shvo}_{2}$ and postoperative liver function. Summary statistics of the measured variables are shown in Table I. In the relationships between mean $\mathrm{ShvO}_{2}$ and max ALT, max total bilirubin, and mean lactate (arterial, hepatic venous, and the difference between them), the critical mean $\mathrm{ShvO}_{2}$ value $\left(\mathrm{x}_{\mathrm{c}}\right)$, as well as the slope of the regression line below the critical point (s), were significantly different from 0 (Fig. 4 and Table II). This means that these hepatic function indices were constant where mean $\mathrm{ShvO}_{2}$ was above the critical mean value $\left(x_{c}\right)$, whereas the indices were linearly correlated with mean $\mathrm{Shvo}_{2}$ where mean $\mathrm{Shvo}_{2}$ was below the critical level $\left(\mathrm{x}_{\mathrm{c}}\right)$. The estimates of critical mean $\mathrm{ShvO}_{2}\left(\mathrm{x}_{\mathrm{c}}\right)$ were in the range of $21 \%$ to $26 \%$ in the relationships. The interpretation of these results is that when mean $\mathrm{ShvO}_{2}$ is decreased below a critical level (approximately 25\%), liver dysfunction is likely to occur, and the severity of liver dysfunction is correlated with mean $\mathrm{ShvO}_{2}$. In the relationship between mean $\mathrm{ShvO}_{2}$ and mean arterial ketone body ratio, the estimate of critical mean $\mathrm{ShvO}_{2}\left(\mathrm{x}_{2}\right)$ was similar $(32 \%)$ but not significantly different from 0 . 
Table I. Summary statistics of the variables

\begin{tabular}{|c|c|c|c|c|c|}
\hline Variable (unit) & $n$ & minimum & maximum & mean & $S D$ \\
\hline \multicolumn{6}{|l|}{ Blood variable } \\
\hline Mean $\mathrm{Hb}(\mathrm{gm} / \mathrm{dl})$ & 15 & 9.1 & 16.7 & 13.9 & 2.1 \\
\hline Mean $\mathrm{ShvO}_{2}(\%)$ & 15 & 5 & 61 & 32 & 19 \\
\hline Mean $\mathrm{SaO}_{2}(\%)$ & 15 & 86 & 99 & 96 & 4 \\
\hline Mean $\mathrm{SvO}_{2}(\%)$ & 15 & 50 & 82 & 65 & 9 \\
\hline \multicolumn{6}{|l|}{ Hepatic function } \\
\hline $\operatorname{Max} \operatorname{ALT}(\mathrm{U} / \mathrm{L})$ & 14 & 8 & 4053 & 1154 & 1522 \\
\hline $\operatorname{Max} \mathrm{TB}(\mathrm{mg} / \mathrm{dl})$ & 15 & 1.1 & 11.5 & 4.4 & 2.8 \\
\hline Mean La (mg/dl) & 13 & 17.1 & 92.8 & 37.9 & 26.5 \\
\hline Mean Lhv (mg/dl) & 13 & 5.4 & 106.3 & 33.5 & 32.9 \\
\hline Mean La-hv (mg/dl) & 13 & -13.5 & 15.6 & 4.4 & 7.4 \\
\hline Mean AKBR & 8 & 0.36 & 1.16 & 0.76 & 0.31 \\
\hline \multicolumn{6}{|l|}{ Hemodynamics } \\
\hline Mean MAP $(\mathrm{mm} \mathrm{Hg})$ & 15 & 51 & 86 & 73 & 9 \\
\hline Mean CVP (mm Hg) & 15 & 12.9 & 20.7 & 17.3 & 2.6 \\
\hline Mean CI $\left(\mathrm{L} / \mathrm{min} / \mathrm{m}^{2}\right)$ & 11 & 1.4 & 4.3 & 2.7 & 0.9 \\
\hline \multicolumn{6}{|l|}{ Dose of supportive drugs } \\
\hline Mean DOA $(\mu \mathrm{g} / \mathrm{kg} / \mathrm{min})$ & 15 & 5 & 9 & 6.3 & 1.4 \\
\hline Mean DOB $(\mu \mathrm{g} / \mathrm{kg} / \mathrm{min})$ & 15 & 0 & 5 & 0.9 & 1.8 \\
\hline Mean ISP (ng $/ \mathrm{kg} / \mathrm{min})$ & 15 & 0 & 40 & 9.8 & 9.4 \\
\hline Mean PGE $_{1}(\mathrm{ng} / \mathrm{kg} / \mathrm{min})$ & 15 & 0 & 60 & 23.5 & 19.8 \\
\hline
\end{tabular}

$H b$, Blood hemoglobin; $\mathrm{ShvO}_{2}$, hepatic venous oxygen saturation; $\mathrm{SaO}_{2}$, arterial oxygen saturation; $\mathrm{SvO}_{2}$, superior vena caval oxygen saturation; $A L T$, alanine aminotransferase; $T B$, total bilirubin; $L a$, arterial lactate; $L h v$, hepatic venous lactate; $L a$ - $h v$, difference between arterial and hepatic venous lactate (La-Lhv); $A K B R$, arterial ketone body ratio; $M A P$, mean arterial pressure; $C V P$, central venous pressure; $C I$, cardiac index; $D O A$, dopamine; $D O B$, dobutamine; $I S P$, isoproterenol; $P G E_{l}$, prostaglandin $\mathrm{E}_{1}$; mean, mean value for the first 24 hours after the operation; max, maximal value during the first week after the operation.

Table II. Results of the broken-line regression analysis

\begin{tabular}{ccccc}
\hline & & \multicolumn{3}{c}{ Broken-line regression parameter } \\
\cline { 3 - 5 } Hepatic function index & $\mathrm{n}$ & $x_{c}$ & $\mathrm{~s}$ & $\dot{y}_{i}$ \\
\hline Max ALT & 14 & $26 \pm 1^{*}(\%)$ & $-263 \pm 18^{*}(\mathrm{U} / \mathrm{L} / \%)$ & $89 \pm 95(\mathrm{U} / \mathrm{L})$ \\
Max TB & 15 & $25 \pm 5^{*}(\%)$ & $-0.31 \pm 0.11 \dagger(\mathrm{mg} / \mathrm{dl} / \%)$ & $2.9 \pm 0.8 \ddagger(\mathrm{mg} / \mathrm{dl})$ \\
Mean La & 13 & $26 \pm 1^{*}(\%)$ & $-4.79 \pm 0.46^{*}(\mathrm{mg} / \mathrm{dl} / \%)$ & $21.3 \pm 2.2^{*}(\mathrm{mg} / \mathrm{dl})$ \\
Mean Lhv & 13 & $25 \pm 2^{*}(\%)$ & $-6.37 \pm 1.20^{*}(\mathrm{mg} / \mathrm{dl} / \%)$ & $14.4 \pm 2.6^{*}(\mathrm{mg} / \mathrm{dl})$ \\
Mean La-hv & 13 & $21 \pm 2^{*}(\%)$ & $1.82 \pm 0.61 \dagger(\mathrm{mg} / \mathrm{dl} / \%)$ & $7.8 \pm 1.3^{*}(\mathrm{mg} / \mathrm{dl})$ \\
AKBR & 8 & $32 \pm 14(\%)$ & $0.04 \pm 0.06(1 / \%)$ & $0.90 \pm 0.12^{*}$
\end{tabular}

Data are estimate \pm standard error of the estimate. $x_{c}$, Critical point in mean Shvo; $s$, slope of the regression line where Shvo $\mathrm{S}_{2} \leq \mathrm{x}_{i} ; y_{i}$, independent (constant) value in hepatic function index where $\mathrm{ShvO}_{2}>\mathrm{x}_{\mathrm{c}}$; Other abbreviations as in Table I.

${ }^{*} p<0,001$ different from 0 .

$\dagger p<0.05$ different from 0 .

$\ddagger p<0.005$ different from 0 .

Instead, we found a linear regression in this relationship $(r=0.71, p<0.05)$. Therefore, the critical point in this relationship is still unknown.

Relationship between $\mathrm{Shvo}_{2}$ and hemodynamics. We examined the relationship between mean $\mathrm{ShvO}_{2}$ and the hemodynamic variables using forward stepwise linear regression. Mean cardiac index was a borderline significant $(p=0.057)$ predictor of mean $\mathrm{ShvO}_{2}$ in the relationship: Mean $\mathrm{ShvO}_{2}=12.7$ mean cardiac index $(\mathrm{L} / \mathrm{min} /$ per square meter $)-3.05(\%)(R=0.589$, standard error of the estimate $=16.2 \%$ ).

\section{Discussion}

We here report that a mean $\mathrm{Shvo}_{2}$ value of less than about $25 \%$ for the first 24 hours after a Fontan operation predicts the occurrence and severity of acute liver dysfunction. In our 15 patients, we found that when $\mathrm{ShvO}_{2}$ was less than about $25 \%$, transaminase and bilirubin concentrations were increased, indicating cell damage, and blood lactate was increased, indicating impaired hepatic lactate metabolism. Furthermore, the lower the $\mathrm{ShvO}_{2}$, the more severe the liver dysfunction. For example, in a patient whose mean 

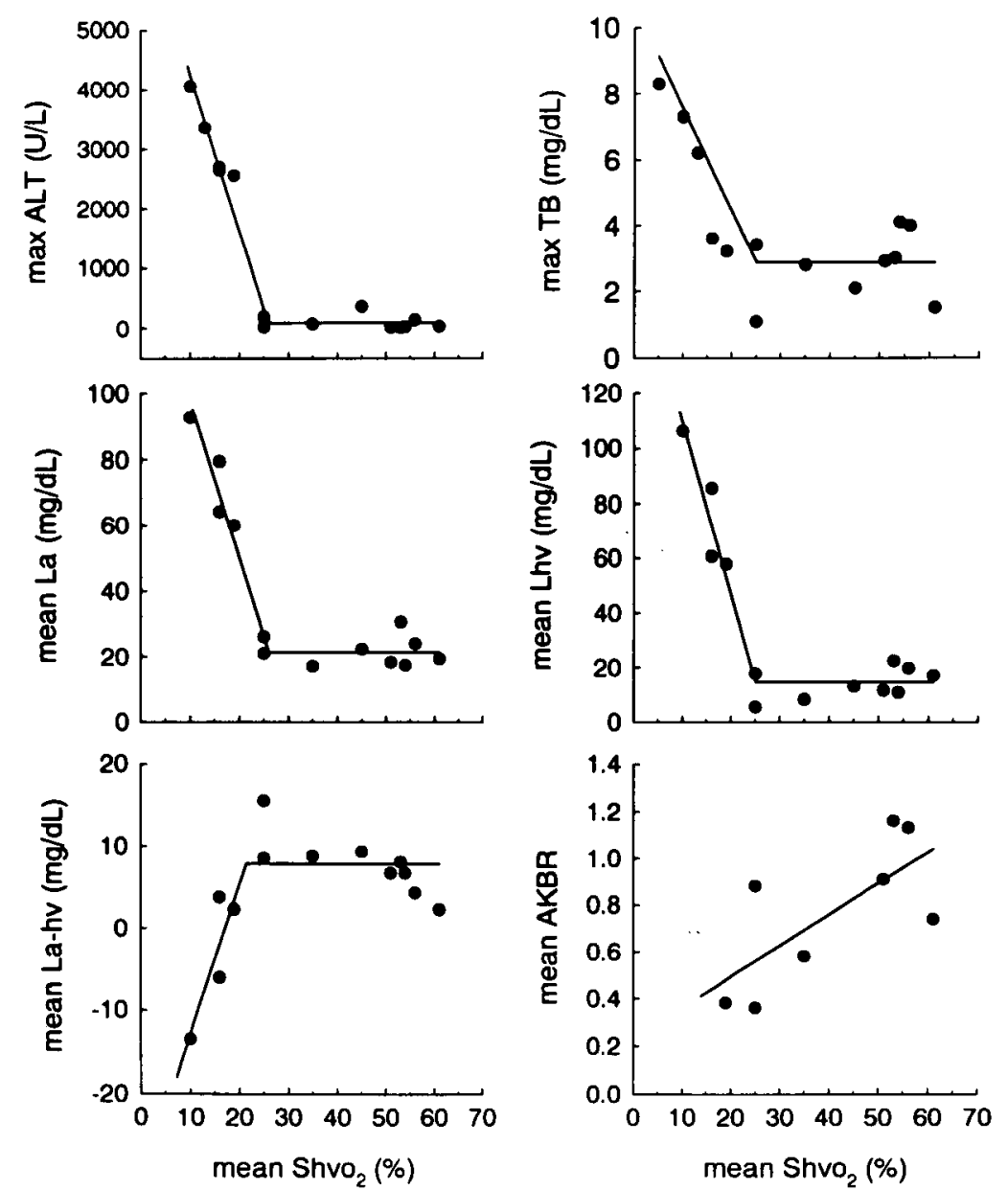

Fig. 4. Relationship between mean $\mathrm{Shvo}_{2}$ and postoperative hepatic function. Shvo ${ }_{2}$, Hepatic venous oxygen saturation; $A L T$, alanine aminotransferase; $T B$, total bilirubin; $L a$, arterial lactate; $L h v$, hepatic venous lactate; $L a-h v$, difference between arterial and hepatic venous lactate; $A K B R$, arterial ketone body ratio; mean, mean value during the first 24 hours after the operation; max, maximal value during the first week after the operation.

$\mathrm{ShvO}_{2}$ was $10 \%$, hepatic function indices had extremely high values: max ALT was $4050 \mathrm{U} / \mathrm{L}$, max total bilirubin $7.3 \mathrm{mg} / \mathrm{dl}$, and mean arterial lactate $93 \mathrm{mg} /$ dl.

Our findings are consistent with those from animal studies, which showed that hepatic functions, such as hepatic lactate uptake, ${ }^{22}$ hepatic oxygen uptake, ${ }^{8,23}$ hepatic ethanol uptake, and bile flow ${ }^{24}$ are impaired when hepatic venous oxygen tension decreases below a range of 5 to $28 \mathrm{~mm} \mathrm{Hg}$.

The main advantage of using $\mathrm{ShvO}_{2}$ to predict acute liver dysfunction is its speed. The standard hepatic function indices, serum enzymes or bilirubin take 24 to 48 hours to increase after the operation. By then, it may be too late to treat these patients successfully. In contrast, $\mathrm{ShvO}_{2}$ clearly detects signs of acute liver dysfunction even during the operation. Treatment can begin immediately and thus has a better chance of success.

Monitoring and treatment were successful in the patients in this study. We monitored $\mathrm{ShvO}_{2}$ continuously with a fiberoptic catheter in five patients and were able to assess the hepatic oxygen supply-demand relationship in real time. Treatment was started during this monitoring even when other hemodynamic variables appeared acceptable, and acute liver dysfunction was prevented (Fig. 5). The optimal treatment is not yet established because the hemodynamic factors that affect $\mathrm{ShvO}_{2}$ are multifactorial. Generally, the treatment is to increase catecholamines when left atrial pressure is high and to use volume loading and pulmonary vasodilation when left atrial pressure is low. However, volume loading may increase CVP and the increase may decrease hepatic 


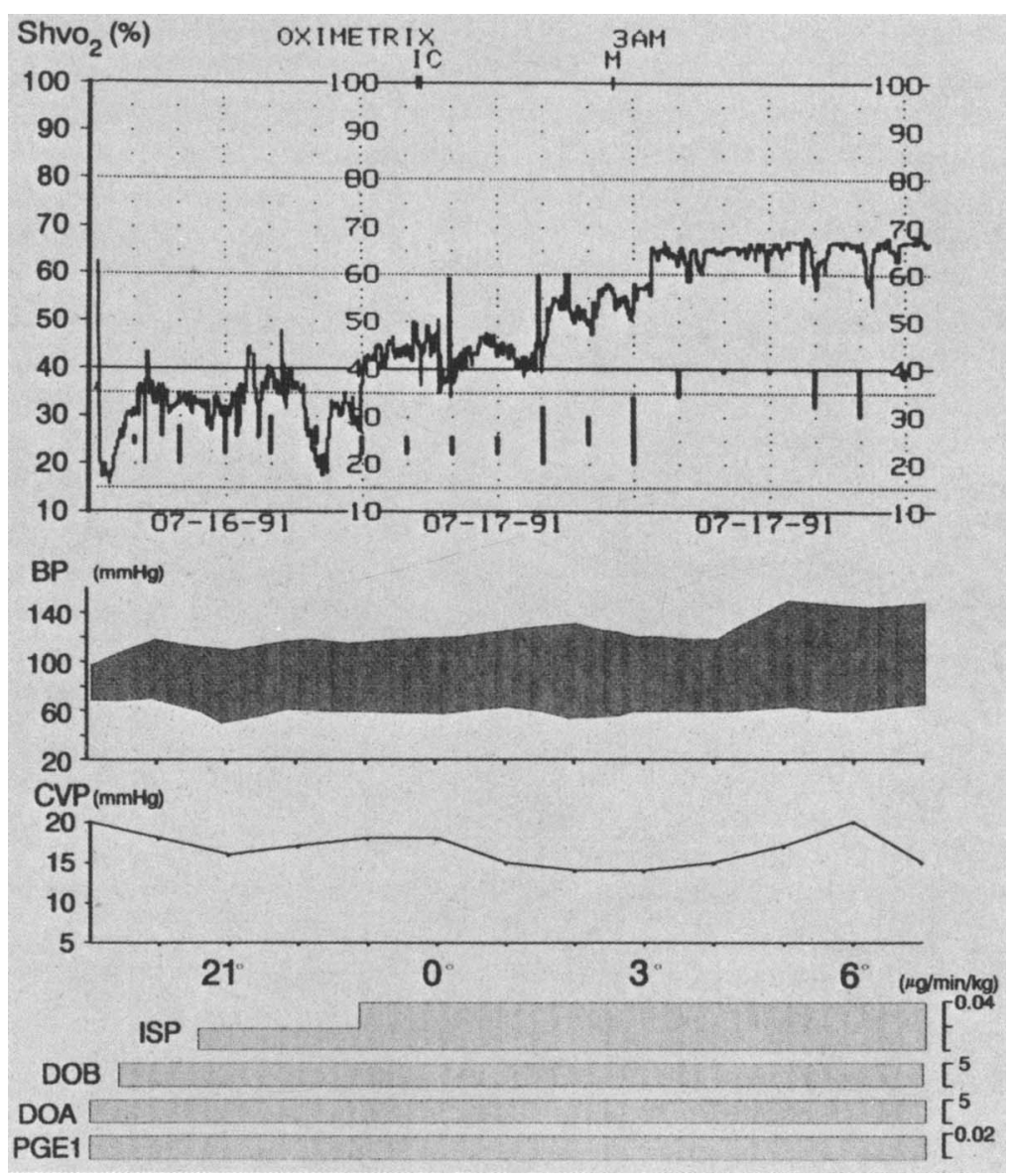

Fig. 5. Continuous $\mathrm{ShvO}_{2}$ monitoring with a fiberoptic catheter. Immediately after the operation, $\mathrm{ShvO}_{2}$ showed markedly low values (below 20\%). Even though the blood pressure seemed to be acceptable, the patient was treated by increasing catecholamines, which led to an increase in $\mathrm{ShvO}_{2}$. In this patient, liver dysfunction did not occur. $\mathrm{ShvO}_{2}$, Hepatic venous oxygen saturation; $B P$, arterial pressure; $C V P$, central venous pressure; $I S P$, isoproterenol; $D O B$, dobutamine; $D O A$, dopamine; $P G E_{l}$, prostaglandin $\mathrm{E}_{1}$.

blood flow. ${ }^{24-26}$ Therefore, careful assessment of the adequacy of the treatment by checking the response of $\mathrm{ShvO}_{2}$ is mandatory.

The major problem in this monitoring is that it requires the invasive technique of hepatic venous catheterization. Although we have not observed any complications relating to hepatic venous catheters, a noninvasive technique to measure the hepatic perfusion state would be better. For example, monitoring arterial lactate or the arterial ketone body ratio, which we used as indices of hepatic function, could be an alternative to monitoring $\mathrm{ShvO}_{2}$. However, at this point, we believe that continuous $\mathrm{ShvO}_{2}$ monitoring is superior because of its fast response, ease of use, and great sensitivity in detecting hepatic hypoperfusion and thus hypoxia.

- In this study, we found only a borderline correlation between $\mathrm{ShvO}_{2}$ and hemodynamic variables. $\mathrm{We}^{4}$ have previously reported that cardiac output may play a more significant role than CVP in causing acute liver dysfunction in patients after Fontan operations. $\mathrm{We}^{9}$ have also shown, in dogs, that abdominal aortic flow contributes more significantly to $\mathrm{ShvO}_{2}$ than inferior vena caval pressure does. From these results, we believe that cardiac output may play an important role in determining $\mathrm{ShvO}_{2}$, although we could not clearly show it in this study. The lack of a significant correlation in the present study might have been due to the fact that we measured cardiac output in 11 of the 15 patients, and less frequently than other hemodynamic variables. Surprisingly, $\mathrm{ShvO}_{2}$ was not correlated with superior vena caval oxygen saturation in this study, a finding that has previously been reported. ${ }^{27,28}$ This finding may indicate that the distribution of cardiac output to each organ changes in situations such as low cardiac output status or an unstable hemodynam- 
ic condition after cardiac surgery. Furthermore, inotropic drugs, which have been reported to alter hepatic blood flow, ${ }^{20,21}$ were not selected as significant variables relating to $\mathrm{ShvO}_{2}$. Thus these drugs probably altered cardiac output or blood pressures but did not have an additional effect on hepatic blood flow in this study.

Some potential limitations of the study merit discussion. First, acute changes in hepatic function precipitated by injury to the liver may begin during rather than after the operation because of cannulation of the inferior vena cava, hypothermia, hypoperfusion, long duration of cardiopulmonary bypass, or other intraoperative factors. It is possible that these intraoperative factors might influence postoperative hepatic function directly (not through postoperative hepatic oxygen supply-demand status). However, this possibility seems unlikely because the patients in our study, who underwent relatively uniform operations and cardiopulmonary bypass procedures, had a variety of postoperative $\mathrm{ShvO}_{2}$ values, and these values correlated significantly with hepatic function. Thus postoperative liver dysfunction in these patients must have been related to postoperative hepatic oxygen supplydemand status rather than to intraoperative factors. Second, although a correlation existed between $\mathrm{ShvO}_{2}$ and early postoperative liver function, this correlation did not signal irreversible liver dysfunction. Most of the patients with low $\mathrm{ShvO}_{2}$ recovered their normal hepatic function late after the operation. Thus one might think that changes in $\mathrm{ShvO}_{2}$ poorly predict long-term liver dysfunction and that the importance of monitoring $\mathrm{ShvO}_{2}$ should be minimized. However, although all our patients who had acute liver dysfunction recovered normal hepatic function, it took more than 1 month for their complete recovery. For example, serum total bilirubin 1 month after the operation was still twice as high in the six patients with an $\mathrm{ShvO}_{2}$ less than $25 \%$ as in the nine patients with an $\mathrm{ShvO}_{2}$ of $25 \%$ or more $(1.9 \pm 0.6$ versus $0.8 \pm 0.2$ $\mathrm{mg} / \mathrm{dl}, p<0.001)$. Moreover, a significant correlation existed between the duration of intensive care unit stay and the mean $\mathrm{Shvo}_{2}\left(r_{s}=-0.75, p=0.002\right)$ as assessed by Spearman rank correlation. Thus the morbidity of the patients with low $\mathrm{ShvO}_{2}$ was greater than that of the patients with higher $\mathrm{ShvO}_{2}$. Therefore we think that monitoring $\mathrm{ShvO}_{2}$ for the prevention of acute liver dysfunction is a useful way to reduce the morbidity of the patients.

In summary, we here report that an $\mathrm{ShvO}_{2}$ value below the critical point of about $25 \%$ for the first 24 hours after a Fontan operation predicts the occurrence and the severity of acute liver dysfunction. Although severe liver dysfunction is rare nowadays because of the use of newer modifications of the Fontan operation, in some patients operative risk is relatively high because of poor ventricular function or high pulmonary vascular resistance. Monitoring $\mathrm{ShvO}_{2}$ may be useful for managing these critically ill patients after Fontan operations.

We thank Stanton A. Glantz, PhD, and Mimi Zeiger (University of California, San Francisco), for statistical advice and helpful comments on drafts of the manuscript, respectively, and Ryo Fushimi and Kikumi Hosotsubo (Osaka University Medical School) for assistance with the alanine aminotransferase, total bilirubin, and lactate measurements.

\section{REFERENCES}

1. Mundth ED, Keller AR, Austen WG. Progressive hepatic and renal failure associated with low cardiac output following open-heart surgery. J THORAC CARDIOVASC SURG 1967;53:275-84.

2. Hill DM, Warren SE, Mitas JA, Swerdlin AHR. Hepatic coma after open heart surgery. South Med J 1980;73: 906-8.

3. Jenkins JG, Lynn AM, Wood AE, Trusler GA, Barker GA. Acute hepatic failure following cardiac operation in children. J THORAC Cardiovasc Surg 1982;84:865-71.

4. Matsuda H, Covino E, Hirose $\mathrm{H}$, et al. Acute liver dysfunction after modified Fontan operation for complex cardiac lesions: analysis of contributing factors and its relation to the early prognosis. J THORAC CARDIOVASC SURG 1988; 96:219-26.

5. Cromme-Dijkhuis $\mathrm{AH}$, Henkens $\mathrm{CM}$, Bijleveld $\mathrm{CM}$, Hillege HL, Bom VJ, van der Meer J. Coagulation factor abnormalities as possible thrombotic risk factors after Fon$\tan$ operations. Lancet 1990;336:1087-90.

6. Nogaki H. Risk factors and management of deteriorated liver function following open-heart surgery in patients with pre-existing congestive liver dysfunction due to heart failure. Nippon Kyobu Geka Gakkai Zasshi 1984;32:1762-74.

7. Onitsuka T, Koga Y, Shibata K, et al. The effects of hepatic perfusion pressure on hepatic insufficiency after open heart surgery for congenital heart disease. Nippon Kyoubu Geka Gakkai Zasshi 1986;34:336-42.

8. Nagano K, Gelman S, Parks DA, Bradley EL Jr. Hepatic oxygen supply-uptake relationship and metabolism during anesthesia in miniature pigs. Anesthesiology 1990;72:90210.

9. Takano H, Nakano S, Shirakura R, Kaneko M, Matsuda H. Experimental assessment of hepatic perfusion in circulatory failure: influence of low cardiac output and high venous pressure. Surg Forum 1991;42:216-8.

10. Williamson DH, Lund P, Krebs HA. The redox state of free nicotinamide-adenine dinucleotide in the cytoplasm and mitochondria of rat liver. Biochem J 1967;103:514-27.

11. Ozawa K, Aoyama H, Yasuda K, et al. Metabolic abnormalities associated with postoperative organ failure: a redox theory. Arch Surg 1983;118:1245-51.

12. Gutmann I, Wahlefeld AW. L-(+)-Lactate. In: Bergmey- 
er HU, ed. Methods of enzymatic analysis. New York: Academic Press, 1974:1464-8.

13. Mellanby J, Williamson DH. Acetoacetate. In: Bergmeyer HU, ed. Methods of enzymatic analysis. New York: Academic Press, 1974:1840-3.

14. Williamson DH, Mellanby J. D-(-)-3-Hydroxybutyrate. In: Bergmeyer HU, ed. Methods of enzymatic analysis. New York: Academic Press, 1974:1836-9.

15. Sherlock $S$. The liver in heart failure: relation of anatomical, functional and circulatory changes. Br Heart J 1951; 13:273-93.

16. Lutz J, Henrich $\mathrm{H}$, Bauereisen E. Oxygen supply and uptake in the liver and the intestine. Pflüegers Arch 1975; 360:7-15.

17. Samsel RW, Cherqui D, Pietrabissa A, et al. Hepatic oxygen and lactate extraction during stagnant hypoxia. J Appl Physiol 1991;70:186-93.

18. Samsel RW, Schumacker PT. Determination of the critical $\mathrm{O}_{2}$ delivery from experimental data: sensitivity to error. J Appl Physiol 1988;64:2074-82.

19. Glantz SA, Slinker BK. Nonlinear regression. In: Glantz SA, ed. The primer of applied regression and analysis of variance. New York: McGraw-Hill, 1990:482-94.

20. Bacq Y, Gaudin C, Hadengue A, et al. Systemic, splanchnic and renal hemodynamic effects of a dopaminergic dose of dopamine in patients with cirrhosis. Hepatology 1991; 14:483-7.
21. Kurokawa T, Nonami T, Harada A, et al. Effects of prostaglandin $E_{1}$ on the recovery of ischemia-induced liver mitochondrial dysfunction in rats with cirrhosis. Scand $\mathbf{J}$ Gastroenterol 1991;26:269-74.

22. Tashkin DP, Goldstein PJ, Simmons DH. Hepatic lactate uptake during decreased liver perfusion and hypoxia. Am J Physiol 1972;223:968-74.

23. Larsen JA, Krarup N, Munck A. Liver hemodynamics and liver function in cats during graded hypoxic hypoxemia. Acta Physiol Scand 1976;98:257-62.

24. Hanson KM, Johnson PC. Local control of hepatic arterial and portal venous flow in the dog. Am J Physiol 1966;211: 712-20.

25. Lautt WW. Effects of acute, passive hepatic congestion on blood flow and oxygen uptake in the intact liver of the cat. Circ Res 1977;41:787-90.

26. Hinshaw LB, Reins DA, Wittmers L. Venous-arteriolar response in the canine liver. Proc Soc Exp Biol Med 1965;118:979-82.

27. Kainuma M, Fujiwara Y, Kimura N, et al. Monitoring hepatic venous hemoglobin oxygen saturation in patients undergoing liver surgery. Anesthesiology 1991;74:49-52.

28. Takano H, Matsuda $H$, Kaneko $M$, et al. Hepatic venous oxygen saturation monitoring in patients with assisted circulation for severe cardiac failure. Artif Organs 1991; $15: 248-52$ 